\title{
Cathepsin B Cleavage of vcMMAE-Based Antibody-Drug Conjugate is not Drug Location or Monoclonal Antibody Carrier Specific
}

Benson Gikanga, ${ }^{\dagger}$ Nia S. Adeniji, ${ }^{\ddagger}$ Thomas W. Patapoff, ${ }^{\S}$ Hung-Wei Chih, ${ }^{\ddagger}$ Li Yi ${ }^{*}, \star$

${ }^{\dagger}$ Pharmaceutical Processing and Technology Development, ${ }^{\dagger}$ Late Stage Pharmaceutical

Development, ${ }^{\S}$ Early Stage Pharmaceutical Development, Genentech Inc.,1 DNA Way, South San Francisco, California 94080, United States

*Corresponding author. Email: yi.li@gene.com.

\section{SUPPORTING INFORMATION}

Table S1. Literature Reported Michaelis-Menten Parameters of Cathepsin B on Various PeptideBased Substrates

Figure S1. pH dependence of cathepsin B activity using ADC I-vc-MMAE as substrate

Figure S2: In silico Frame of a DAR 8 ADC during a 213ns Trajectory (val + cit components of vcMMAE (green) shown in red, see web-enhanced content for $360^{\circ}$ rotation of this structure)

Figure S3. vc Fractional SASA timecourse for select ADC DAR 8 conjugation sites 
Table S1. Literature Reported Michaelis-Menten Parameters of Cathepsin B on Various Peptide-Based Substrates

\begin{tabular}{ccccc}
\hline Substrate & Assay condition & $\boldsymbol{k}_{\text {cat }}(\mathbf{s - 1})$ & $\mathbf{K}_{\boldsymbol{M}}(\boldsymbol{\mu M})$ & Reference \\
\hline Z-RR-NNap & $\mathrm{pH} 6.0,40^{\circ} \mathrm{C}$ & 61 & 191 & 17 \\
& $\mathrm{pH} 5.6,25^{\circ} \mathrm{C}$ & 77 & 108 & 22 \\
Z-RR-NMec & $\mathrm{pH} 6.0,40^{\circ} \mathrm{C}$ & 158 & 184 & 14 \\
& $\mathrm{pH} 5.5,37^{\circ} \mathrm{C}$ & $52-75$ & $114-125$ & 16 \\
Z-RR-pNa & $\mathrm{pH} 6.0,24^{\circ} \mathrm{C}$ & $10-13$ & $900-1190$ & 24,26 \\
Z-RR-AMC & $\mathrm{pH} 5.0,25^{\circ} \mathrm{C}$ & $16-43$ & $393-563$ & 25 \\
Z-FR-NMec & $\mathrm{pH} 6.0,40^{\circ} \mathrm{C}$ & 364 & 252 & 14 \\
Z-FR-pNa & $\mathrm{pH} 6.0,24^{\circ} \mathrm{C}$ & $34-37$ & $600-700$ & 24,26 \\
Z-VKKR-NNap & $\mathrm{pH} 6.0,24^{\circ} \mathrm{C}$ & 68 & 140 & 40 \\
PQAF $\left(\mathrm{NO}_{2}\right) \mathrm{G}$ & $\mathrm{pH} 4.9,25^{\circ} \mathrm{C}$ & 2.6 & 140 & 20 \\
QQAF(NO 2$) \mathrm{F}\left(\mathrm{NO}_{2}\right)$ & $\mathrm{pH} 4.9,25^{\circ} \mathrm{C}$ & 0.93 & 240 & 20 \\
\hline
\end{tabular}

$\mathrm{Z}=$ benzyloxycarbonyl; NNap $=\mathrm{N}$-naphthylamide; $\mathrm{NMec}=\mathrm{N}$-methylcourmarylamide; $\mathrm{pNa}=p$ nitroanilides; $\mathrm{AMC}=7$-amido-4-methylcoumarin hydrochloride 


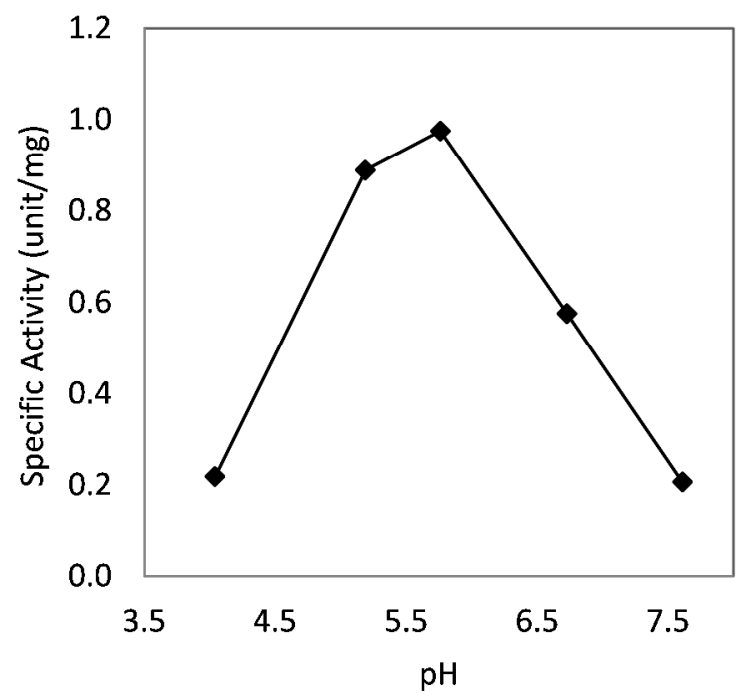

Figure S1. pH dependence of cathepsin B activity using ADC I-vc-MMAE as substrate 


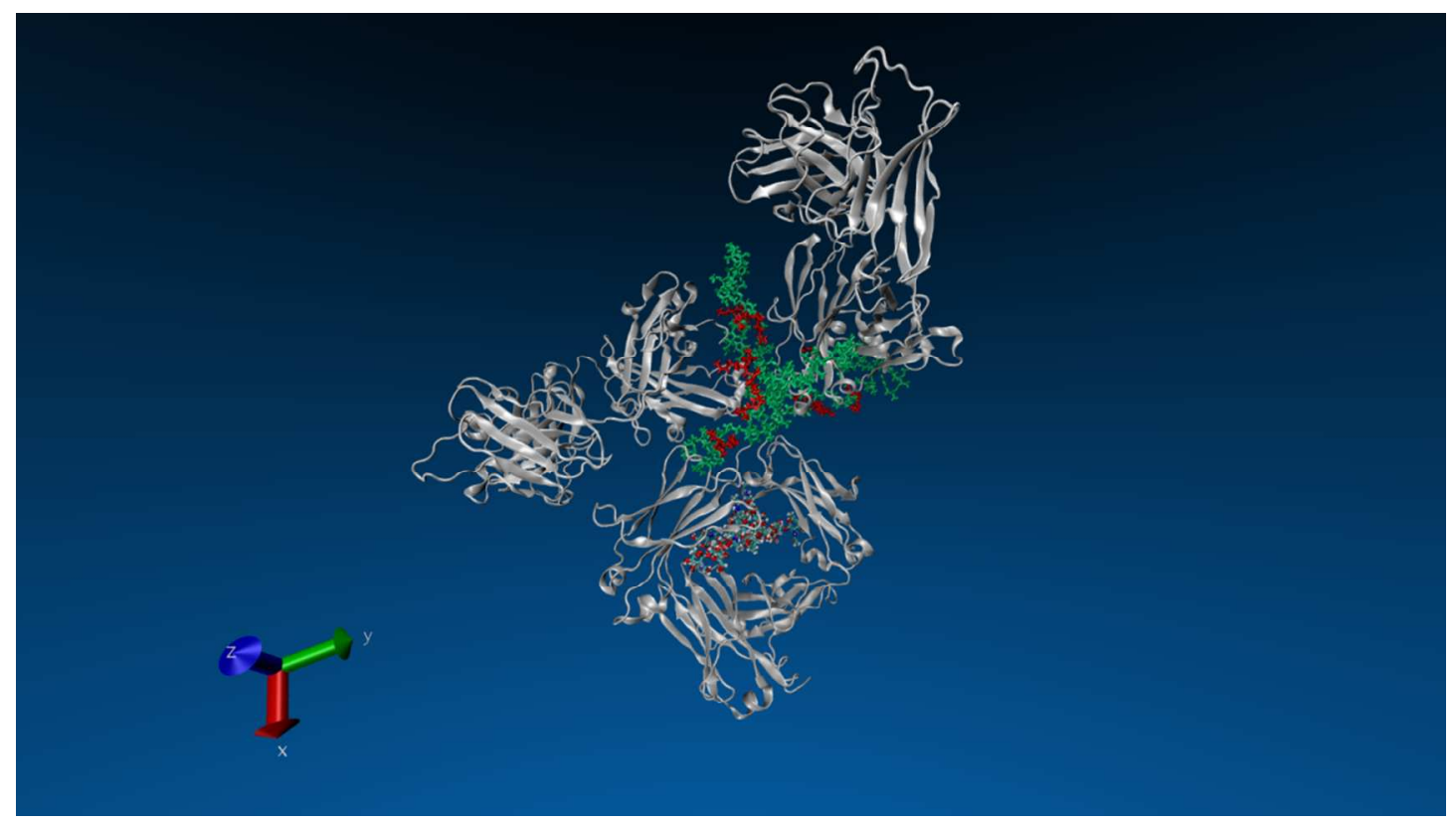

Figure S2: In silico Frame of a DAR 8 ADC during a 213ns Trajectory (val + cit components of $\operatorname{vcMMAE}$ (green) shown in red, see web-enhanced content for $360^{\circ}$ rotation of this structure) 


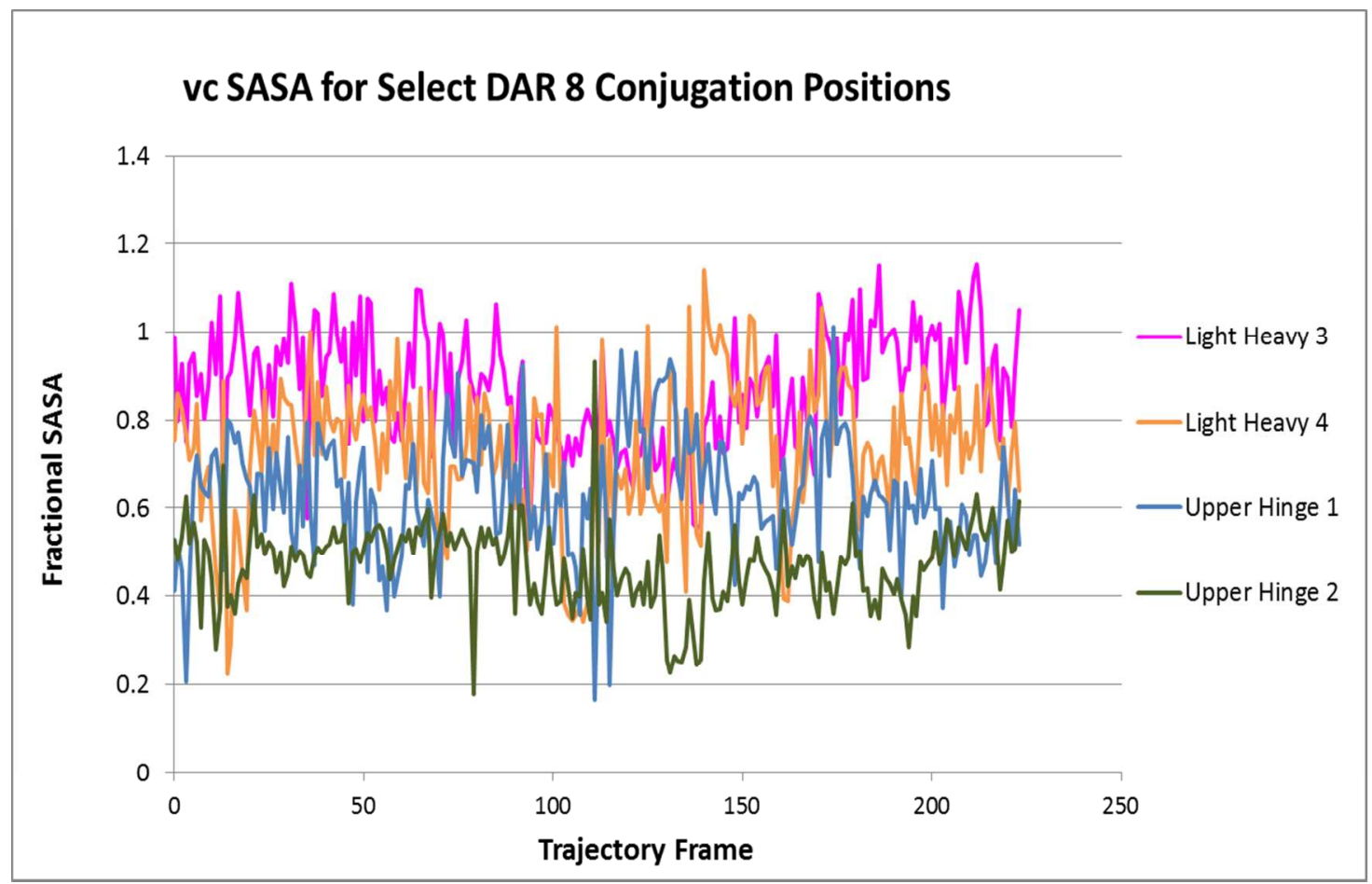

Figure S3. vc Fractional SASA timecourse for select ADC DAR 8 conjugation sites 


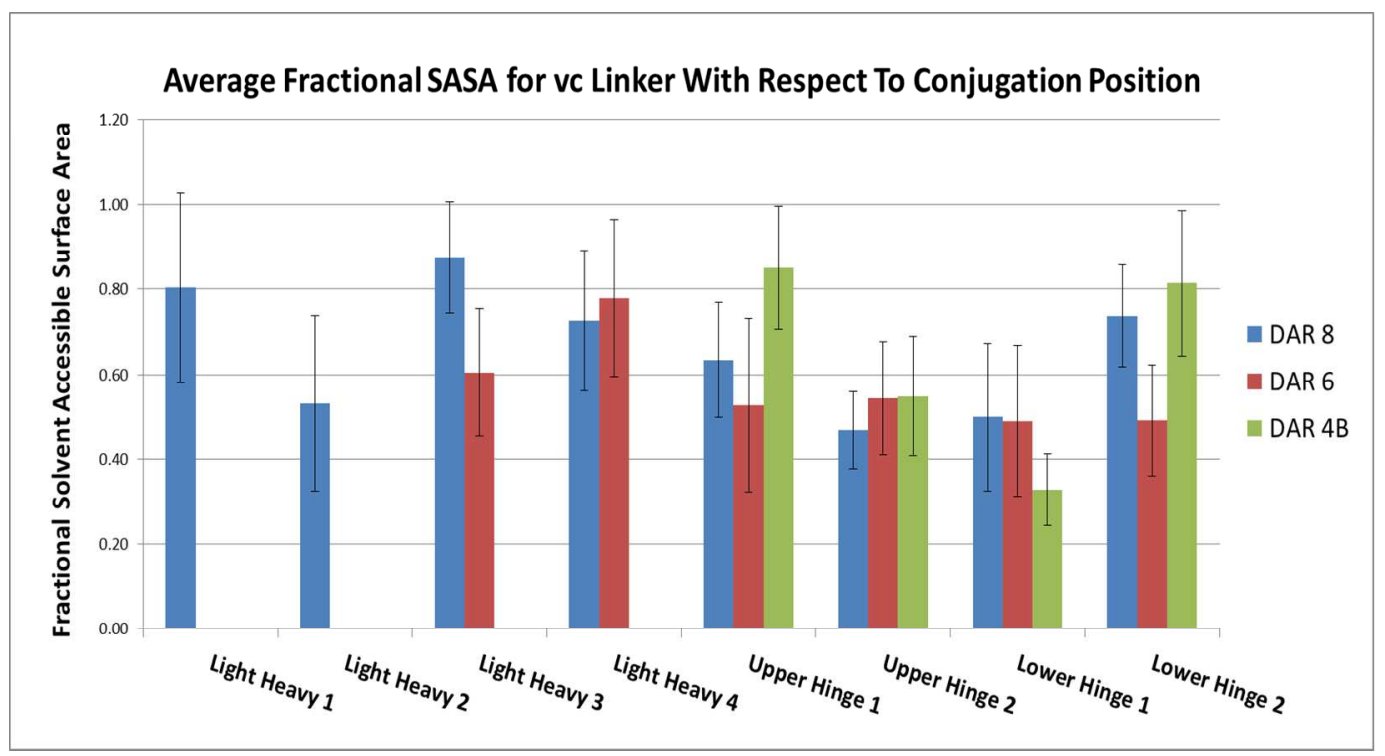

Figure S4. Average ve fractional SASA values ADC DAR 8 conjugation sites 